\title{
Dream time and real time'
}

\section{DAVID KOULACK ${ }^{2}$, STATE UNIVERSITY OF NEW YORK, DOWNSTATE MEDICAL CENTER}

The relationship between real time and $R E M$-dream time was explored by asking Ss to judge the length of time from an incorporation of an external stimulus (percutaneous shocks to the median nerve at the wrist) to their awakening as either $30 \mathrm{sec}$ or $3 \mathrm{~min}$. Ss' ability to make this discrimination was taken as support of the notion that a relationship may exist between $R E M$-dream time and real time.

In 1861, Maury reported a lengthy dream that took place in Paris during the Reign of Terror. He witnessed a number of murders and was brought to trial himself and condemned to be guillotined. He climbed up to the scaffold, and after being bound, felt the blade of the guillotine separate his head from his body. He woke up in extreme anxiety to find that the top of his bed had fallen and struck him on the neck just the way the blade of the guillotine would have struck. From this dream, which he believed to have been initiated by the blow on his neck, he came to the conclusion that the length of dreams in real time is extremely short, with many events often being telescoped into this relatively brief interval.

In 1960 , Schjelderup hypnotically induced relatively lengthy dreams during a period of 1 to $2 \mathrm{sec}$ of hypnotically induced sleep. He took these findings to be a confirmation of a notion akin to Maury's that the velocity of creation and combination of images during dreaming exceeds the occurrence of those events during physical time; i.e., that the extent of time spent dreaming is in no way related to the length of the reported dream.

However, work by Dement \& Kleitman (1957) suggests that there may be a relation between the length of dreams and the length of real time spent dreaming. They awakened Ss from rapid eye movement (REM) periods, those periods of sleep from which dream reports are most often elicited (Aserinsky \& Kleitman, 1953), at 5 or $15 \mathrm{~min}$ intervals after their onset, and asked them to judge whether they had been dreaming for 5 or $15 \mathrm{~min}$. All but one of their Ss made judgments in direct correspondence to the length of the REM period from which they had been awakened.

A subtle philosophical argument has been raised concerning the conclusiveness of this evidence (Malcolm, 1962). The main point of the argument is that since the dreamer and the observer have only the dreamer's account of the experience in common, there is no basis for making a judgment about the actual time of occurrence of the experience or its duration. That is, this situation is not like the waking state where both the experiencer and the observer have access to a particular event and hence can measure its duration or time of occurrence by reference to a clock. The present experiment was designed to meet this objection by supplying both the dreamer and the observer with a common reference point in real time.

Subjects. Ten adult males ranging in age from 20 to 40 years were paid to serve as Ss. Half of the Ss were night employees of the U.S. Post Office and the New York Transit Authority, who slept in the laboratory during the day, while half were night sleepers; and of these, four were college students and one a professional actor.

Apparatus. The Ss slept in an air-conditioned, sound-proof bedroom. An adjoining recording laboratory contained an 8-channel Grass EEG Model-IIID console connected to the bedroom by a bedside plugboard. A bedside telephone enabled the $S$ to communicate with the $E$ in the laboratory, and picking up the telephone automatically turned off an $85 \mathrm{~dB}$ buzzer used for awakenings during the night. ${ }^{3} \mathrm{~A}$ tape recorder in the laboratory was used to record all conversations during the night.

A constant current stimulator ${ }^{4}$ was used to generate a 6 -msec electrical pulse to the median nerve of either the right or left wrist of the Ss.
Procedure. The external stimulus was presented to the Ss either immediately after or $3 \mathrm{~min}$ after the first eye movement of a REM period. The stimulus used consisted of six percutaneous shocks to the median nerve at the wrist presented at $2.5 \mathrm{sec}$ intervals at a level of intensity high enough to elicit a thumb jerk during the waking state. This stimulus intensity level has been shown to elicit an evoked cortical response in all stages of sleep (Goff, Allison, Shapiro, \& Rosner, 1966).

The $\mathrm{S}$ was awakened either $30 \mathrm{sec}$ or $3 \mathrm{~min}$ after the end of the stimulation of either the right or the left wrist. The $S$ was instructed to report immediately what had been going through his mind just prior to the awakening. There were no questions by $E$ until the end of this initial report.

In those instances where $\mathrm{E}$ could identify clearly the presence of the stimulus in the dream report and there was no evidence of concomitant waking alpha in the EEG record, $S$ was asked to estimate if that event had occurred more nearly $30 \mathrm{sec}$ before the buzzer or more nearly $3 \mathrm{~min}$ before the buzzer. An example of one such instance is as follows: "...I started walking back here to tell you about it. I metcha in the hall and I told you, Hey Dave, this thing here is ... I'm feeling the electrical impulses without electricity going through. I felt it about three or four times. On my left hand... then I realized I was in my underwear all along ..."

So, for example, in this instance the question would be: "Did you feel the electrical impulses more nearly $30 \mathrm{sec}$ before the buzzer sounded or more nearly 3 min before the buzzer sounded?"

Results and Discussion. There were 12 instances obtained from five of the Ss where the presence of the stimulus in the dream could be identified clearly; $92 \%$ of S-judgments (11 of 12) placed those incidents at a time corresponding to the time of stimulation.

This ability of the dreamer to discriminate between the times of occurrence of externally induced events in the REM-dream helps to place those events in real time. Although these discriminations are of a rather gross nature, they are in accordance with the finding by Dement and Kleitman of correspondence between Ss' judgments of time spent dreaming and the length of the REM periods from which they were awakened; and also, they support their notion that a relationship may exist between REM-dream time and real time.

\section{REFERENCES}

ASERINSKY, E., \& KLEITMAN, N. Regularly occurring periods of eye motility and concomitant phenomena during sleep. Science. 1953, 118 , 273-274.

DEMENT, W., \& KLEITMAN, N. Cyclic variations in EEG during sleep and their relation to eye movements, body motility, and dreaming. Electroenceph. clin. Neurophysiol. 1957, 9, 673-690.

GOFF, W. R., ALLISON, T., SHAPIRO, A., \& ROSNER, B. S. Cerebral somatosensory responses evoked during sleep in man. Electroenceph. clin. Neurophysiol. 1966, 21, 1-9.

MALCOLM, N. Dreaming. New York: Humanities Press, 1962.

MAURY, L. F. A. Le sommeil et les reves. Paris: 1861.

SCHJELDERUP, H. K. Time relations in dreams. Scand. J. Psychol., 1960, $1,62-64$.

\section{NOTES}

1. The research reported in this paper was conducted in the Psychology Laboratory of the Department of Psychiatry, State University of New York, Downstate Medical Center. It was supported by a grant (M-628) from the United States Public Health Service National Institutes of Health. I wish to thank both Dr. H. A. Witkin and Dr. M. Eagle for their interest and helpful suggestions. Portions of this paper were presented at the annual meeting of the Association for the Psychophysiological Study of Sleep, Santa Monica, California, April, 1967

2. Now at Department of Psychology, Washington State University, Pullman, Washington 99163 .

3. "Night" throughout this paper refers to the time spent sleeping in the laboratory, regardless of whether it was actually during the day or at night.

4. The constant current stimulator was designed by H. Cohen, A. Fecci, and A. Shapiro. 